\title{
Treatments Based on Phenotypic Variants in Chronic Obstructive Pulmonary Disease
}

\section{Kamyar Afshar*}

Division of Pulmonary and Critical Care, University of Southern California, Keck School of Medicine, USA

Referring physicians may ask, "My patient with COPD is on her inhalers, so why does she continue to complain of worsened shortness of breath?"

Chronic Obstructive Pulmonary Disease (COPD) is characterized by progressive airflow limitation that is not fully reversible. Patients are stratified into low and high risk based on severity of airflow limitation (GOLD stages) and/or number of annual exacerbations [1]. Although COPD is the fourth leading cause of death, it is still underdiagnosed and frequently misunderstood $[2,3]$. Even when individuals have been diagnosed appropriately with COPD, the phenotypic variants (eg. emphysema, chronic bronchitis, etc.) may not be fully appreciated. Even within the same phenotypes, there is heterogeneity with symptomatology, physiological parameters and radiographic appearance. Ultimately, this may lead to sub-optimal management resulting in increased rate of exacerbations, disease progression and ultimately death.

Evaluation of the overall health of a COPD patient is shifting focus towards utilizing both subjective (St. George's respiratory questionnaire, COPD Assessment Test, modified Medical Research Council (MMRC) dyspnea scale) and objective physiological parameters (spirometry, lung volumes, diffusion capacity, 6-minute walk distance) [4]. This provides anintegrated evaluation of symptom burden and risk of exacerbation and mortality.

There is ample evidence for the association of COPD exacerbations and decline in lung function [5]. Importantly, it has been shown that successive severe exacerbations are more frequent, intervals between exacerbations are less ("clustering of exacerbations") and severity of the exacerbation increases following the first severe exacerbation [6]. The major contributing risk factor for frequent exacerbations in all GOLD stages is a history of exacerbation [7]. Therefore, key strategy to successful management of COPD is a concerted effort to reduce exacerbation rates.

A number of trials have evaluated therapies to either reduce decline in lung function or reduce exacerbation rates [8-12]. However, trends in lung function decline were not significantly better in the treatment groups compared to the placebo group. With respect to the UPLIFT and TORCH studies, the treatment groups did have a $14-16 \%$ reduction in exacerbation rates. A potential criticism of these studies is that all phenotypes were lumped together for analysis. Future studies will most likely delve into therapeutic benefits in specific sub-populations.

Nonetheless, general recommendations remain to counsel patients on tobacco cessation, remainupdated on immunizations, enroll in pulmonary rehabilitation and be on combination therapy with a long acting beta- ${ }_{2}$ agonist (LABA), Long Acting Muscarinic Antagonists (LAMA) and inhaled corticosteroids [1]. However, not all COPD is the same and perhaps should not be treated the same.This may be illustrated by the studies withroflumilast.Roflumilast, a phosphodiesterase- 4 inhibitor, reduces airway inflammation. In two randomized clinical trials in a bronchitic COPD phenotype, comparing roflumilast $500 \mu \mathrm{g}$ once daily to placebo over a 52-week period, $\mathrm{FEV}_{1}, \mathrm{FVC}$ and mid-flow volumes improved along with a $16 \%$ reduction in exacerbations $[13,14]$. These effects were independent of concomitant inhalation medications or smoking status.
With respect to $\alpha_{1}$-antitrypsin (AAT) deficiency, augmentation therapy is an additional therapeutic regimen that has been evaluated, but not administered consistently. Augmentation therapy is recommended in patients with $\alpha_{1}$-antitrypsin (AAT) deficiency with serum AAT levels $<11.0 \mu \mathrm{M}$ and $\mathrm{FEV}_{1}$ between $25-30 \%$ predicted at the lower limits and $65-80 \%$ predicted at the upper limits $[15,16]$. Although treatment with augmentation therapy has not reduced lung function deterioration, or frequency of exacerbation, it has reduced the severity of exacerbations [17]. An additional randomized controlled trial addressing the question of mortality benefits with augmentation therapy has recently ended enrollment and we look forward to results [18].

Lung volume reduction surgery has been a therapeutic option in selected patients with heterogenous lung involvement in emphysema. It improves dyspnea, lung function, exercise tolerance and prolongs life in selected patients [19]. It is not benign however. Perioperative death and post-operative complications have lead to less invasive procedures to allow for similar benefits while minimizing risks [20,21]. Endobronchial one-way valves (EBV) are being utilized to achieve similar goals without the need to undergo surgery. EBVs are reserved for advanced heterogenous emphysema. Successful placement of EBVshas been shown to improve lung function, dyspnea and exercise tolerance, but exacerbation episodes were more frequent post procedure compared to the control group who received standard medical therapy [22]. It has been proposed that the EBV itself may not be the contributing factor to developing an exacerbation as much as self-discontinuation of inhalation therapies.

In summary, it is proven that pulmonary rehabilitation, smoking cessation and preventive immunizations are beneficial in all sub-types of COPD. We know that exacerbations greatly contribute to disease progression, increase subsequent exacerbation severity and frequency, profoundly limit functional capacity and increase mortality.Future trials require re-evaluation of the currently recommended combination therapies with LAMA, LABA and ICS in specific subpopulations. A number of considerations should be taken into account when evaluating the status of the COPD patient. Most important, health care providers should be proactive in identifying the COPD phenotype and make attempts to limit exacerbation events based on targeted therapies. Hopefully molecular profiling can also assist us in identifying COPD subtypes to better provide targeted therapies.

${ }^{*}$ Corresponding author: Kamyar Afshar, Assistant Professor of Clinical Medicine Division of Pulmonary and Critical Care, University of Southern California, Keck School of Medicine, 2020 Zonal Ave, IRD 723, Los Angeles, CA 90033, USA, Tel: 323-226-7923; Fax: 323-226-2873; E-mail: kafshar@usc.edu

Received June 03, 2013; Accepted June 05, 2013; Published June 07, 2013

Citation: Afshar K (2013) Treatments Based on Phenotypic Variants in Chronic Obstructive Pulmonary Disease. J Pulm Respir Med 3: e128. doi:10.4172/2161 105X. 1000e128

Copyright: (c) 2013 Afshar K. This is an open-access article distributed under the terms of the Creative Commons Attribution License, which permits unrestricted use, distribution, and reproduction in any medium, provided the original author and source are credited. 
Citation: Afshar K (2013) Treatments Based on Phenotypic Variants in Chronic Obstructive Pulmonary Disease. J Pulm Respir Med 3: e128. doi:10.4172/2161-105X. 1000e128

\section{References}

1. Global strategy for the diagnosis, management, and prevention of COPD: Revised 2011. Global initiative for chronic obstructive lung disease (GOLD).

2. Lopez AD, Shibuya K, Rao C, Mathers CD, Hansell AL, et al. (2006) Chronic obstructive pulmonary disease: current burden and future projections. Eur Respir J 27: 397-412.

3. Sandelowsky H, Ställberg B, Nager A, Hasselström J (2011) The prevalence of undiagnosed chronic obstructive pulmonary disease in a primary care population with respiratory tract infections - a case finding study. BMC Fam Pract 12: 122.

4. Celli BR, Cote CG, Marin JM, Casanova C, Montes de Oca M, et al. (2004) The body-mass index, airflow obstruction, dyspnea, and exercise capacity index in chronic obstructive pulmonary disease. N Engl J Med 350: 1005-1012.

5. Donaldson GC, Seemungal TA, Bhowmik A, Wedzicha JA (2002) Relationship between exacerbation frequency and lung function decline in chronic obstructive pulmonary disease. Thorax 57: 847-852.

6. Suissa S, Dell'Aniello S, Ernst P (2012) Long-term natural history of chronic obstructive pulmonary disease: severe exacerbations and mortality. Thorax 67 : 957-963.

7. Hurst JR, Vestbo J, Anzueto A, Locantore N, Müllerova H, et al. (2010) Susceptibility to exacerbation in chronic obstructive pulmonary disease. N Engl J Med 363: 1128-1138.

8. Lung Health Study Research Group (2000) Effect of inhaled triamcinolone on the decline in pulmonary function in chronic obstructive pulmonary disease. $\mathrm{N}$ Engl J Med 343: 1902-1909.

9. Pauwels RA, Löfdahl CG, Laitinen LA, Schouten JP, Postma DS, et al. (1999) Long-term treatment with inhaled budesonide in persons with mild chronic obstructive pulmonary disease who continue smoking. European Respiratory Society Study on Chronic Obstructive Pulmonary Disease. N Engl J Med 340: 1948-1953.

10. Burge PS, Calverley PM, Jones PW, Spencer S, Anderson JA, et al. (2000) Randomised, double blind, placebo controlled study of fluticasone propionate in patients with moderate to severe chronic obstructive pulmonary disease: the ISOLDE trial. BMJ 320: 1297-1303.

11. Tashkin DP, Celli B, Senn S, Burkhart D, Kesten S, et al. (2008) A 4-year trial of tiotropium in chronic obstructive pulmonary disease. N Engl J Med 359: 15431554.
12. Calverley PM, Anderson JA, Celli B, Ferguson GT, Jenkins C, et al. (2007) Salmeterol and fluticasone propionate and survival in chronic obstructive pulmonary disease. N Engl J Med 356: 775-789.

13. Calverley PM, Rabe KF, Goehring UM, Kristiansen S, Fabbri LM, et al. (2009) Roflumilast in symptomatic chronic obstructive pulmonary disease: two randomised clinical trials. Lancet 374: 685-694.

14. Fabbri LM, Calverley PM, Izquierdo-Alonso JL, Bundschuh DS, Brose M, et al. (2009) Roflumilast in moderate-to-severe chronic obstructive pulmonary disease treated with longacting bronchodilators: two randomised clinical trials. Lancet 374: 695-703.

15. Marciniuk DD, Hernandez P, Balter M, Bourbeau J, Chapman KR, et al. (2012 Alpha-1 antitrypsin deficiency targeted testing and augmentation therapy: a Canadian Thoracic Society clinical practice guideline. Can Respir J 19: 109116

16. American Thoracic Society; European Respiratory Society (2003) American Thoracic Society/European Respiratory Society statement: standards for the diagnosis and management of individuals with alpha-1 antitrypsin deficiency. Am J Respir Crit Care Med 168: 818-900.

17. Dirksen A, Piitulainen E, Parr DG, Deng C, Wencker M, et al. (2009) Exploring the role of CT densitometry: a randomised study of augmentation therapy in alpha1-antitrypsin deficiency. Eur Respir J 33: 1345-1353.

18. ClinicalTrials.gov Identifier: NCT00261833. Zemaira in Subjects With Emphysema Due to Alpha1-Proteinase Inhibitor (API) Deficiency

19. Fishman A, Martinez F, Naunheim K, Piantadosi S, Wise R, et al. (2003) A randomized trial comparing lung-volume-reduction surgery with medical therapy for severe emphysema. N Engl J Med 348: 2059-2073.

20. Naunheim KS, Wood DE, Krasna MJ, DeCamp MM Jr, Ginsburg ME, et al. (2006) Predictors of operative mortality and cardiopulmonary morbidity in the National Emphysema Treatment Trial. J Thorac Cardiovasc Surg 131: 43-53.

21. Naunheim KS (2007) Lung-volume reduction surgery: a vanishing operation? J Thorac Cardiovasc Surg 133: 1412-1413.

22. Sciurba FC, Ernst A, Herth FJ, Strange C, Criner GJ, et al. (2010) A randomized study of endobronchial valves for advanced emphysema. N Engl J Med 363 1233-1244. 